\title{
Effects of naloxone on upper airway collapsibility in normal sleeping subjects
}

\author{
Jean-Claude Meurice, Isabelle Marc, Frédéric Sériès
}

\begin{abstract}
Background - To evaluate the possible influence of endorphin release on upper airway collapsibility the effects of naloxone, an opiate receptor antagonist, were measured.

Methods - The effects of naloxone on upper airway collapsibility were studied in five normal sleeping men in a pilot study. During a sleep fragmentation night the subjects received either naloxone or a volume matched saline placebo in a double blind crossover design. Critical pressure (Pcrit) was measured during a morning nap following sleep fragmentation.

Results - The plasma levels of endorphins increased during sleep fragmentation nights. Pcrit was significantly greater after placebo than after naloxone infusion. Conclusions - Naloxone may reduce upper airway collapsibility in normal sleeping subjects following sleep fragmentation. (Thorax 1996;51:851-852)
\end{abstract}

Keywords: sleep apnoea/hypopnoea syndrome, endorphins, upper airway dilators, sleep fragmentation.

Changes in upper airway collapsibility play an important part in the development of upper airway closure. ${ }^{1}$ Sleep deprivation worsens sleep-related breathing disturbances. ${ }^{2}$ In the sleep apnoea/hypopnoea syndrome apnoeainduced arousals are associated with sleep fragmentation rather than sleep deprivation. Collapsibility of the upper airway is greater after sleep fragmentation than after sleep deprivation. ${ }^{3}$ Because of the central depressive effect of endorphins and the linkage between the central respiratory and upper airway control systems, we postulated that the endogenous release of opioids during sleep fragmentation could affect the stability of the upper airway. To evaluate the possible influence of endorphin release on upper airway collapsibility we studied the effects of an opiate receptor antagonist, naloxone, on the upper airway of normal subjects during a daytime nap after sleep fragmentation.

Methods

PATIENTS

Five healthy men aged 27-31 years with normal polysomnographic parameters were enrolled. The protocol was approved by the Institutional Research Board; written informed consent was obtained from each subject.

\section{SLEEP FRAGMENTATION}

Sleep fragmentation was achieved by auditory induced recurrent arousals as previously described. ${ }^{3}$ The total recording time was increased during the sleep fragmentation nights until the total sleep time was the same as during the baseline sleep study.

\section{STUDY DESIGN}

Collapsibility of the upper airway was measured during a morning nap 1-1.5 hours after the end of the sleep fragmentation night on two different occasions one week apart. During the sleep fragmentation night subjects were given intravenously either naloxone $(0.1 \mathrm{mg} / \mathrm{kg}$ over five minutes just before sleep onset followed by a continuous infusion of $0.05 \mathrm{mg} / \mathrm{kg} / \mathrm{hour}$ throughout the night) or a volume-matched saline placebo in a randomised crossover double blind design. The infusion was stopped at the end of the night. Plasma levels of $\beta$-endorphins were measured at the beginning and the end of the fragmentation night, before the patient got out of bed.

\section{PRESSURE-FLOW MEASUREMENTS}

Collapsibility of the upper airway was measured during continuous negative airway pressure (CNAP) trials. $^{13}$ Mask pressure (Pm), oesophageal pressure (Poes) referenced to $\mathrm{Pm}$, and instantaneous flow were recorded simultaneously. All measurements were performed in the supine position.

During the CNAP trials the maximal inspiratory airflow (VImax) was measured for each inspiratory cycle in which the flow signal became maximal and plateaued while Poes still increased. The relationship between the breath-by-breath values of VImax and the corresponding $\mathrm{Pm}$ was examined by least squares linear regression analysis and the critical pressure (Pcrit) corresponding to the $\mathrm{Pm}$ where VImax $=0$ was determined.

\section{ANALYSIS OF DATA}

Sleep architecture on each night was compared by a multivariate randomised block design test. Naloxone and placebo arousal indices and Pcrit values were compared using a paired $t$ 
test. Levels of $\beta$-endorphins before and after the sleep fragmentation night were obtained at each visit and compared by a repeated measures analysis of variance (ANOVA) with a considered statistically significant for multivariate tests. For sleep variables each variable was separately analysed with the Bonferonni correction and a $\mathrm{p}$ value of $<0.0125$ was considered of statistical significance.

\section{Results}

There was no difference in total sleep time between the baseline and sleep fragmentation recordings. The arousal index increased from a mean (SD) of $8.0(4.5)$ /hour at baseline to 39.0 (3.9)/hour after placebo and 38.4 (8.6)/hour after naloxone. Sleep fragmentation was associated with an increase in sleep stages I-II and a dramatic reduction in stages III-IV and REM compared with baseline $(\mathrm{p}=0.001)$, with no difference between the naloxone and placebo fragmentation nights. No difference was seen in the characteristics of the auditory stimuli used for sleep fragmentation between the naloxone and placebo sleep studies.

Flow limited respiratory cycles were observed during each CNAP trial. A significant linear relationship was seen between individual values of VImax and $\operatorname{Pm}(R=0.53-0.82$; $\mathrm{p}$ $<0.02)$. The individual Pcrit values obtained at each visit are shown in figure 1 . Pcrit was significantly higher after placebo than after naloxone infusion $\left(-10.2\right.$ (3.6) $\mathrm{cm} \mathrm{H}_{2} \mathrm{O}$ and -16.7 (5.5) $\mathrm{cm} \mathrm{H}_{2} \mathrm{O}$, respectively; $\mathrm{p}=0.02$ ). The mean slope of the pressure-flow relationship was $43(27) \mathrm{ml} / \mathrm{s} / \mathrm{cm} \mathrm{H}_{2} \mathrm{O}$ after placebo and $24(12) \mathrm{ml} / \mathrm{s} / \mathrm{cm} \mathrm{H}_{2} \mathrm{O}$ after naloxone. The levels of $\beta$-endorphins increased significantly from the beginning to the end of the sleep fragmentation nights (placebo: before 8.6 (4.4) $\mathrm{pg} / \mathrm{ml}$, after 14.2 (3.1) pg/ml; naloxone: before 5.9 (4.5) $\mathrm{pg} / \mathrm{ml}$, after 13.5 (3.8) $\mathrm{pg} / \mathrm{ml}$; $\mathrm{p}<0.005)$. The increase in endorphin levels was higher following naloxone than placebo $(\mathrm{p}<0.05)$.

\section{Discussion}

Sleep fragmentation was associated with a significant increase in plasma endorphin concentrations. The physiological circadian changes in endorphin release are far less than those reported following sleep fragmentation, ${ }^{4}$ which suggests that recurrent sleep disruption further

Figure 1 Individual and mean values of the critical pressure (Pcrit) measured after placebo and naloxone infusions. Pcrit was significantly lower after naloxone than after placebo $* p<0.05$. profile analysis. A $p$ value of $<0.05$ was

increases endorphin release during sleep. The greater increase in the release of endorphins following naloxone compared with placebo is consistent with a negative feedback mechanism which enhances the release of endorphins in response to opioid receptor blockade.

The opiate antagonist effects of naloxone have been extensively studied to evaluate the influence of $\beta$-endorphins on ventilatory control in awake subjects. In patients with chronic obstructive pulmonary disease naloxone restores a compensatory response to flow resistive loading. ${ }^{5}$ Opioid receptors are localised in the area of the brainstem that is closely associated with the central control of breathing. Since the central respiratory and upper airway control systems are closely linked, the observed increase in upper airway collapsibility could be accounted for by the effects of endorphins on control of the respiratory and upper airway dilator muscles, with a preferential detrimental effect on pharyngeal muscle activity. Naloxone tended to reduce the slope of the pressure-flow relationship with a simultaneous reduction in upper airway collapsibility. This is consistent with the improvement in the early response to an inspiratory flow resistive load observed with naloxone, ${ }^{6}$ and suggests that naloxone could increase the reflex load response of the upper airway dilator muscles leading to a greater activation of these dilator muscles as $\mathrm{Pm}$ decreases.

We conclude that naloxone improves upper airway collapsibility in normal sleeping subjects. A previous study of the sleep apnoea/ hypopnoea syndrome found a decrease in the average maximal oxyhaemoglobin desaturation $^{7}$ and an increase in the ventilatory compensation following apnoea ${ }^{8}$ with naloxone infusion, but failed to demonstrate any improvement in the apnoea/hypopnoea index. ${ }^{8}$ This suggests that alteration of the reflex pressure load response of upper airway dilator muscles is not a determining factor in the increase in upper airway collapsibility in these patients.

This study was supported by the respiratory health network of the Centres of Excellence of Canada. Dr J-C Meurice was a recipient of the postdoctoral Boehringer Ingelheim/SPLF training award.

1 Schwartz AR, Smith PL, Wise RA, Gold AR, Permutt S. Induction of upper airway occlusion in sleeping individuals with subatmospheric nasal pressure. ff Appl Physiol 1988;64:535-42

2 Guilleminault C. Sleep apnoea syndromes; impact of sleep and sleep states. Sleep 1980;3:227-34.

3 Sériès F, Roy N, Marc I. Effects of sleep deprivation and sleep fragmentation on upper airway collapsibility in normal subjects. Am $f$ Respir Crit Care Med 1994; 150:481-5.

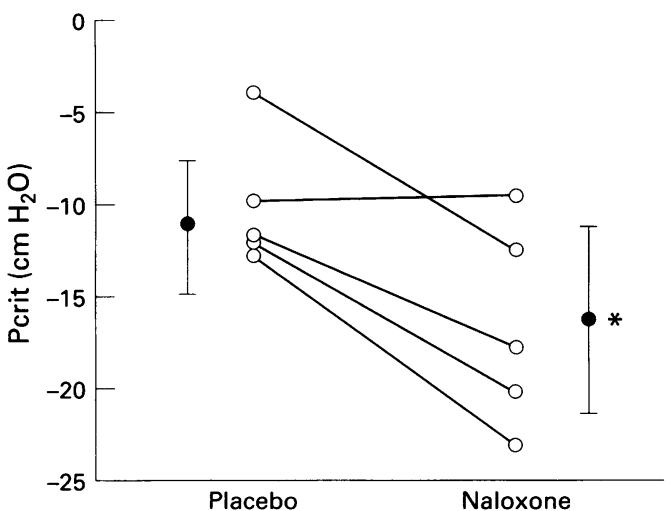

Petraglia F, Facchinetti F, Parrini D, Micieli G, De Luca S, Genazzi AR Simultaneous circadian variation of plasma ACTH Beta endorphin and cortisol. Hormone Res 1983;17:147-52.

5 Santiago TV, Remolina C, Scoles V, Edelman NH. Endorphins and the control of breathing. Ability of naloxone to restore flow-resistive load compensation in chronic obstructive pulmonary disease. $N$ Engl $f$ Med 1981;304:1190-5.

6 Scardella AT, Santiago TV, Edelman NH. Naloxone alters the early response to an inspiratory flow-resistive load. $\mathcal{f}$ Appl Physiol 1989;67:1747-53.

7 Atkinson RL, Suratt PM, Wilhoit SC, Recant L. Naloxone improves sleep apnoea in obese humans. Int $\mathcal{f}$ Obesity 1985;9:233-9.

8 Greenberg HE, Rapoport DM, Rothenberg A, Kanengiser LA, Norman RG, Goldring RM. Endogenous opiates modulate the postapnea ventilatory response in the modulative sleep apnea syndrome. Am Rev Respir Dis $1991 ; 143: 1282-7$. 